\title{
Sexual orientation discrimination in hiring
}

\author{
Doris Weichselbaumer* \\ Department of Economics, University of Linz, Altenbergerstr. 69, 4040 Linz, Austria
}

Received 3 January 2002; received in revised form 28 April 2003; accepted 2 June 2003

\begin{abstract}
Little research has been done to examine discrimination against gays and lesbians in the labor market. Wage regressions have documented lower incomes for gays but repeatedly showed higher incomes for lesbians. The results concerning lesbian women are striking but can be reconciled with the existence of labor market discrimination, however. Problems like sample selection and unobserved heterogeneity — in particular, lesbians' violation of stereotypical female gender rolesmight be responsible for their higher earnings.

To investigate whether discrimination against lesbians actually does exist, a labor market experiment is conducted. Job applications of candidates, who are equivalent in their human capital but differ in their sexual orientation, are sent out in response to job advertisements. Furthermore, to test whether increased masculinity affects labor market outcomes, the applicants differ in their perceived gender identity.

While results show a strong negative effect for lesbian orientation, gender identity does not have a significant overall impact on hiring chances.

(C) 2003 Elsevier B.V. All rights reserved.
\end{abstract}

JEL classification: C93; J15; J71

Keywords: Discrimination; Sexual orientation; Experimental economics

\section{Introduction}

A number of demographic groups are reported to be affected by labor market discrimination: women, ethnic and national minorities, disabled workers, as well as religious and sexual minorities have been observed to face unfavorable labor market outcomes. Most studies on discrimination focus on earnings differentials by race or gender since corresponding data is more readily available. Nevertheless, not only do these groups

* Tel.: +43-732-2468-8240; fax: +43-732-2468-9679.

E-mail address: doris.weichselbaumer@jku.at (D. Weichselbaumer). 
represent merely a fraction of the possibly discriminated population, but discrimination can also take on different forms, i.e. can also occur in hiring, promotion and firing.

This study investigates discrimination against lesbians in hiring. The demographic group of lesbian workers is of particular interest, since-contrary to other social minorities, including gay men - they have repeatedly been shown to earn higher wages than their reference group, i.e. heterosexual women (see, e.g. Black et al., 2003; Blandford, 2003; Plug and Berkhout, in press). ${ }^{1}$ However, despite their apparently privileged labor market status, $16-46 \%$ of gay and lesbian survey respondents report to have experienced some form of labor market discrimination (see Badgett et al., 1992, for a review of surveys). These seemingly contradictory findings can be reconciled, however. A number of reasons suggest that lesbians' earnings are overestimated, most importantly because of unobserved heterogeneity and statistical reasons.

The adopted gender role of lesbians and heterosexual women is one example for such unobserved differences in characteristics. Lesbians are documented as often behaving in more manly ways and being more masculine, i.e. more dominant, autonomous, assertive and detached than heterosexual women (see Riess et al., 1974). It has been argued that since employers adhere to the ideal of masculinity which is associated with labor market success, lesbians might be financially rewarded in contrast to heterosexual women (see Blandford, 2003; Clain and Leppel, 2001).

However, lesbians might deviate from heterosexual women also in other dimensions. In particular, lesbians have been shown not to adhere to the traditional division of labor within the household where primarily one partner is responsible for household tasks. ${ }^{2}$ This is economically rational, since members of same-sex relations often have similar abilities and labor market opportunities which do not allow them to make use of comparative advantages. Furthermore, since most countries do not offer a legal substitute for marriage, specializing in house work becomes a risky choice. Since lesbian couples rear children less frequently, there is less need for a homemaker as well. As a result of reduced household responsibilities, lesbians might be more productive in the workplace and obtain higher wages than heterosexual women. The lack of children also makes higher investments in on-the-job-training profitable since lesbians expect a more continuous labor market participation than heterosexual women. Such higher on-the-job-training, unobservable in the data, might be another reason for the observed higher pay.

In addition to unobserved heterogeneity, there are statistical reasons which bias lesbians' earnings upwards. Blandford (2003) reports that lesbian and bisexual women are more successful in entering male-dominated, well-paid occupations than their heterosexual peers and suggests that even controlling for occupations at the two-digit level might be insufficient to capture all effects of occupational clustering. Consequently, some of lesbians' higher incomes might be attributable to job subcategories which are not adequately captured by the data. Furthermore, it is most probable that the analyzed data suffer from sample selection bias. Higher income individuals are more willing to disclose their lesbian orientation. As a result, their observed earnings are upwardly biased. Last but not least, the empirical data suffers from one additional major drawback: Available data

\footnotetext{
1 For an review of studies on wage differentials based on sexual orientation, see Badgett (2002).

2 For a review of the literature, see Giddings (in press).
} 
sets do not provide information about disclosure at the workplace, which is a precondition for direct labor market discrimination by employers. Many gays and lesbians choose not to reveal their sexual orientation on the job to avoid mobbing and employment discrimination, and pass as heterosexuals. Badgett (1996) reports from survey data that significantly fewer lesbians out themselves on the job than gay men. This might be another reason why, on average, lesbians do not suffer from the same income loss as gay men.

Due to these specific flaws in the available data, empirical research examining wage differentials, although highly interesting, cannot inform about labor market discrimination against equally productive gays and lesbians. From a policy perspective, however-e.g. when fighting direct discrimination or advising gays and lesbians whether to come outthe existence and amount of direct employer discrimination is crucial.

This paper takes a different route to assess differential treatment by using an experimental technique to gather representative data on labor market outcomes of lesbians. Labor market experiments can best be used to investigate discrimination in hiring and have the advantage that typical problems of earnings regressions can be avoided.

\section{Experimental investigation}

The crucial advantage of an experiment is the full control the researcher has over her data. In particular, identical productivity as well as sexual orientation of workers can be controlled for by the experimenter. Therefore, a carefully setup design allows to test for what is of central interest: direct discrimination against openly lesbian employees with equal productivity compared to the heterosexual control group, without having one's data flawed by sample selection and unobserved heterogeneity.

In this study we use a common experimental method called Correspondence Testing to examine the hiring chances of lesbians. Résumés of applicants who were matched in all relevant productive characteristics, like age, schooling and job experience, but differed in their indicated sexual preference, were sent out in response to job advertisements. All candidates indicated being single in their CVs to avoid any differences in expected productivity. If one applicant was invited to an interview by an employer, while the other was not, this was assigned to discrimination. With this technique, the labor market outcomes of two identical individuals of equal productivity, who only differ in respect to their demographic group, can be compared directly. ${ }^{3}$

As has been noted before, some economists (Blandford, 2003; Clain and Leppel, 2001) have suggested that lesbians' increased masculinity, their similarity to the stereotypical male, is responsible for their relatively high incomes. Masculinity (being assertive, dominant, etc. $)^{4}$ might either constitute a productive personality trait in the labor market, or employers simply have preferences for more masculine workers. Since

\footnotetext{
3 Certainly this experimental method does impose some costs on the employer, as résumés of applicants who are actually not available have to be evaluated, but these costs are not infrequent, as workers often want to test their outside opportunities to increase their bargaining situation at the current job (Riach and Rich, 1995).

4 Bem (1974) specifies the following characteristics as commonly being perceived as "typically male": acts as a leader, aggressive, ambitious, analytical, assertive, athletic, competitive, defends own beliefs, dominant, forceful, has leadership abilities, independent, individualistic, makes decisions easily, masculine, self-reliant, selfsufficient, strong personality, willing to take a stand, willing to take a risk.
} 
our experiment gave us full control over workers' characteristics, we wanted to investigate whether those "masculine characteristics" can actually explain lesbians" higher earnings. We found this question particularly interesting, since psychologists have previously argued that one of the reasons why lesbians are disliked is their frequent violation of gender stereotypes and display of "inappropriate" gender mannerisms ("butch" and "femme"). Laner and Laner (1980) found that it is personal style as well as sexual preference that triggers a dislike of gays and lesbians. They showed that when a lesbian performs average heterosexual femininity, this in fact reduces dislike against her. Consequently, masculinity might not only be beneficial but could as well trigger a taste for discrimination.

\section{Different treatment when equally productive?}

A number of reasons why direct discrimination based on sexual orientation might occur are conceivable. In comparison to race and sex discrimination, unfavorable treatment is less likely to be motivated by employers' beliefs in different group averages of productivity, i.e. statistical discrimination (Phelps, 1972; Arrow, 1973). Gays and lesbians are the only social minority that is actually brought up within a majority culture (by heterosexual parents) and cannot be identified solely by their looks (skin color, sex). ${ }^{5}$ In contrast to females and ethnic minorities, gays and lesbians are socialized according to "majority norms", already from birth on. Consequently, they are most likely to match the social majority group, i.e. heterosexuals, in their average productivity. If anything, statistical discrimination should work in favor of the lesbian! Lesbians are not only better equipped in observables, the fact that they earn more on average even when controlling for observables reflects that they are also doing better in the unobservables. In particular, the fact that they are less likely to drop out of the labor market due to child birth should make them attractive employees. Therefore, we should expect preferential treatment due to positive statistical discrimination. This would only reduce the amount of discrimination we observe, and Beckerian discrimination, in fact, is underestimated.

When controlling for productive characteristics and gender identity - which might differ for gay/lesbian and heterosexual individuals and cause differences in productivitymost unfavorable treatment can be assigned to a distaste of working with gays and lesbians because of a disapproval of their sexual orientation. Following Becker's (1957) taste for discrimination model, entrepreneurs might have a preference to work with heterosexual employees, and if they maximize utility and not profits, they are prepared to hire them, even if they are of lower productivity or have higher reservation wages. Similarly, coworkers' dislikes to working with gays and lesbians might lead to unfavorable treatment. Various surveys indicate that such a dislike against gay and lesbian workers in fact does exist. Black et al. (2003) report that in the General Social Survey data, " $83 \%$ of men and $80 \%$ of women responded that same-sex sexual relations are 'always wrong' or 'usually wrong'." Klawitter and Flatt (1998) give an overview of numerous opinion polls and find that around $20 \%$ of Americans do not favor equal job opportunities for gays and

\footnotetext{
5 Other examples for characteristics, which are unobservable and employers might have preferences for, are religion or national origin (Badgett, 1995).
} 
lesbians. Nevertheless, the support for equal job opportunities has increased from less than $60 \%$ in the late 1970 s to around $80 \%$ in the 1990 s.

\section{Method}

Correspondence Testing has been widely used to measure race (e.g. Newman, 1978; Firth, 1981; Riach and Rich, 1991) and sex discrimination (Firth, 1982; Riach and Rich, 1995). Adam (1981) used a similar technique for testing discrimination based on sexual orientation. While very interesting in extending the research to a previously neglected area of discrimination, his study has more the touch of a pilot study with its rather small sample and lack of statistical information.

Correspondence Testing allows to compare the labor market outcomes of applicants who are identical in all their productive characteristics but differ in one demographic variable. The necessary data is gained by sending out matched letters of applications to the same job openings. If a firm invites one applicant but not another, then this can be attributed to discrimination. ${ }^{6}$ Similar experiments have been used to examine the treatment of same-sex and opposite-sex couples by salespersons' in stores (Walters and Curran, 1996) and by hotels' when requiring a weekend reservation for a room with one bed only (Jones, 1996).

Usually conducted in America, Australia or Great Britain, previous studies using Correspondence Testing suffer from the general drawback that only very short résumés are common in these countries, a fact which possibly does not allow controlling for all relevant variables. Consequently, the possibility of mere statistical discrimination cannot be ruled out (see Heckman, 1998). ${ }^{7}$ The Austrian labor market, on the other hand, has the advantage that this problem can be avoided without raising employers' suspicion. ${ }^{8}$ In Austria, a very detailed set of documents is required to be considered a serious job

6 Obviously testing whether somebody gets invited for an interview captures differential treatment at the initial stage of hiring only, while some employers might delay their "discriminatory activity" until later. Still, the possibility of receiving a job offer is conditional on being invited to an interview, which means that differential treatment in hiring has to be equal or larger to what is measured by Correspondence Testing (Riach and Rich, 1995). Researchers at the Urban Institute (e.g. Kenney and Wissoker, 1994) have extended this method to the next stage of the hiring process. In their "Audit Studies", they have not only sent out written applications but also matched pairs of real applicants of different ethnic groups who actually met employers for an interview. This allows the observing of discrimination in actual job offers, although it suffers from the disadvantage that real-life applicants who meet all the required criteria are hard to find. Furthermore, it is impossible to control for differences in real-life interactions that might take place during an interview. "Audit Studies" have also been conducted to measure discrimination in housing, applying for a mortgage, negotiating the price of a car and seeking taxi services (see Fix et al., 1993 for an overview of auditing for discrimination).

7 When testing for discrimination based on sexual orientation this is generally a less severe problem, however, since — as has been stated before - there seems to be little prejudice about gays' and lesbians' productivity. If there are no presumed differences in productivity, no statistical discrimination can occur.

8 Austria has not yet adopted any anti-discrimination policies protecting gays and lesbians against unfair treatment in the labor market, in contrast to 12 states and many cities in the US and most other countries in the European Union that already have anti-discrimination laws. However, a directive by the European Union in autumn 2000 imposes the implementation of such a national law upon Austria within a time frame of three years. 
applicant. Ideally, the letter of application is supplemented by a curriculum vitae, school reports, letters of reference by previous employers, and a photograph. This vast amount of information largely dismisses the possibility of mere statistical discrimination. A similarly convincing experiment could not be conducted in the US without a great risk of being detected.

To test for discrimination based on sexual orientation and identify whether gender has a mediating effect on differential treatment, a $2 \times 2$ experimental design has been used, varying sexuality (heterosexual/lesbian identity) and gender (femininity/masculinity) of the applicants. Consequently, application material had to be constructed for four different types: a heterosexual (straight) feminine and straight masculine woman, a feminine lesbian ("femme"), and a masculine lesbian ("butch").

\subsection{Gender types}

To meet Austrian standards, the application material consisted of a letter of application, an elaborate curriculum vitae, a fake school report and a photograph. Obviously, the need to attach photographs of equally good-looking applicants made the preparation of the application material considerably more demanding, but also served as an advantage for the research question: physical looks are one of the strongest indicators for gender identity and could be used as a signal accordingly. While the masculine woman depicted in the photo had short, dark hair, broad shoulders and was wearing a business jacket, the feminine one had long, blond hair and was in elegant, flowing clothes.

Other indicators for gender identity were the following: choice of font and layout in the $\mathrm{CV}$ and hobbies. The layout of the feminine applicant's CV was nice and playful, the design of the masculine appeared rather plain. The feminine female's hobbies were drawing, designing and making of clothes, while the masculine enjoyed rock-climbing, canoeing, playing drums, and motorcycling. ${ }^{10}$

A pre-test was conducted to verify the successful representation of the two females' gender identity and to ensure that the differences of all job applicants in their selfpresentation (in particular the photographs) did not cause distortions in general desirability. One hundred nineteen business students were asked to evaluate one applicant each, represented by her $\mathrm{CV}$ and photo. There was no information on sexual orientation given for the candidates. The Bem Sex-Role Inventory ${ }^{11}$ used is a standard measure for gender identity in psychology and provides a sufficient tool to test the dimensions "femininity", "masculinity", and "social desirability". While the feminine female achieved significantly higher scores in femininity and the masculine female in

\footnotetext{
9 Detailed application materials (standard letters of application, CVs, school reports and photographs) are available from the author upon request.

${ }^{10}$ In addition, different international job experiences (au pair girl for the feminine, motorcycle tour with occasional jobs for the masculine female) were given for accountants, one of the two occupational subcategories tested. Since they were of higher age than the secretaries (matched to the average employee in the occupation), it was possible to indicate one-and-a-half years international experience for both applicants without evoking too much suspicion. See Weichselbaumer (in press) for details.

11 See Bem (1974) for description.
} 
masculinity, the scores of the two candidates on social desirability were almost identical. $^{12}$

\subsection{Sexual orientation types}

For half of the applicants no explicit information on sexual orientation was given, these were classified as heterosexuals. The lesbians were labeled by the following information about their secondary occupation: "1996-1998: Managerial activity for the Viennese Gay People's Alliance." To indicate that this personal engagement in the gay and lesbian movement would not conflict with job dedication, the affiliation with the Gay People's Alliance already laid in the past. ${ }^{13}$ In contrast to many other gay and lesbian organizations around the world, the Austrian Gay People's Alliance has no affinities to any political party but represents gays and lesbians of all political and religious convictions. To signal a similar amount of social awareness, this commitment to volunteer work by the lesbians was juxtaposed by matching statements for the straight applicants, varied for different gender identities. The feminine straight woman declared to volunteer for a nonprofit organization assisting school children with learning disabilities and the masculine woman for a nonprofit cultural center.

The different sexuality/gender types were simply created by combining the gendered $\mathrm{CVs}$ with the sexual orientation information.

The application letters were constructed to match the average employee in the clerical profession, i.e. accountant and secretary. ${ }^{14}$ This occupational category was chosen because the relatively high labor demand allowed sending out a sufficient number of standardized applications in response to job advertisements to gather a representative sample. Furthermore, it allowed to create convincing application material (e.g. by providing school

12 Only one previous study using Correspondence Testing, Newman (1978), reported the attachment of photographs, and was severely criticized for not controlling for physical attractiveness of the applicants (see McIntyre et al., 1980). Since a number of studies have shown that beauty has an impact on labor market decisions (e.g. Hamermesh and Biddle, 1994; 1998; Averett and Korenman, 1996), it seemed important to add physical attractiveness as a separate item to the social desirability dimension provided by the Bem Sex-Role Inventory. Similarly, the item "making a competent impression" was included to ensure that photographs and other variations in the CVs did not cause one applicant to look relatively more proficient than the other. For details on scores of applicants and statistical tests, see Weichselbaumer (in press).

13 Some employers might not discriminate against lesbians per se, but only against those who list participation in gay and lesbian organizations on their CVs. They may perceive the lesbian applicant as a radical or as lacking business savvy, since she does not try to hide her sexual orientation more actively. However, previous professional engagement with a gay and lesbian organization clearly serves as an indicator for relevant job experience, so hiding sexual orientation means either concealing relevant human capital or lying about one's past with the risk of being detected.

In previous experiments, authors indicated sexual orientation by affectionate behavior of the individuals (holding hands, talking to one another smiling) (Walters and Curran, 1996) or by couples requesting a room with one bed only in a hotel (Jones, 1996).

14 Both of these jobs are female-dominated ones: $77 \%$ of all accountants and $97 \%$ of all secretaries are women. The average income of women in both occupations is $€ 1000$ according to the Micro Census 1997; the average overall female income is $€ 900$ (male: $€ 1300$ ). Weichselbaumer (in press) has tested the effect of sex and gender conformity of heterosexual applicants not only for female- but also for male-dominated occupations and found discrimination by sex but not by gender. 
reports), and to submit written applications (in many occupations, phone calls are required to test the verbal fluency of applicants).

To avoid detection, names of employers were avoided in the CVs and job experience was formulated in a rather general way. All accountants and secretaries had identical human capital and obtained their education in exactly the same school-type, only at different locations. The school marks in the attached school reports were identical for all applicants in those subjects of primary relevance for the jobs under investigation and equal on average in subjects of lower interest. The photograph was attached in the form of a (digitally manipulated) image color-printed on the $\mathrm{CV}$, which is a common cost-saving practice used by Austrian job applicants.

\subsection{Sending out the applications}

While it is not an absolute necessity to send all the different applications to each firm, it serves the advantage of controlling for firm-specific variables. ${ }^{15}$ Besides that it allows to collect data more quickly.

In principle, the most straightforward experiment to test for discrimination based on sexual orientation would be to send applications of all four different applicants, the feminine straight (FS), the masculine straight (MS), the feminine lesbian (FL) and the masculine lesbian (ML), to the same vacancies and compare the invitation rates. Evaluating the success rates for an identical woman who one time indicates she is a lesbian, and the other time does not, would allow to measure the effect of sexual orientation. At the same time, a comparison of the feminine and masculine female of one particular sexual orientation could be used to calculate the effect of gender. However, the actual research setup faces a special problem: two identical applications of a single individual — one time labeled as lesbian, the other time not — cannot be sent to the same firm. They would be immediately identified as representing one single person instead of being evaluated independently. Particularly, the photograph leads to an instantaneous recognition of the identical applicant. Similarly, it is not possible to send the applications of the two lesbians to one firm. Employers would certainly detect the "coincidence" of two applicants declaring themselves as lesbians at the same time! Consequently, we had to choose a more indirect route to gain the desired data. First, we collected data comparing the two heterosexual women, then we submitted applications by one heterosexual and one lesbian with differing gender identity to each firm under investigation. This avoided the problem of detection, but still allowed to control for firm-specific variables.

The Saturday issue of the Austrian newspaper "Kurier" was examined weekly for relevant job advertisements, as it provides the largest amount of job announcements from the biggest Austrian labor market, the Greater Vienna area.

The experiment was conducted in three different steps: from early to late 1998, all the firms searching for accountants or secretaries were contacted by the two straight women

15 Adam (1981) sent only one résumé to each firm, which does not control for firm specific effects, but allows using completely identical letters of application instead of creating matching ones, since there is no danger of detection. 
(round 1). In the next step, from late 1998 to mid-1999, applications of the feminine straight and masculine lesbian women were sent to all vacancies (round 2). Finally, from mid-1999 to early 2000, the feminine lesbian and masculine straight woman applied to all announced vacancies (round 3). In total, 1226 applications were sent out in response to 613 job openings.

If an entrepreneur was interested in one of the applicants, she could be contacted either through a Viennese address, or by leaving a message on her answering machine. When one of the applicants was invited to an interview, the proposed appointment was canceled to avoid any inconveniences on the firm's side.

\section{Results}

\subsection{Discrimination against masculine woman}

Table 1 shows the invitation rates of the different applicants. Table 1a illustrates the effect of sexual orientation on the masculine woman. First, the pair of straight females with different gender identity applied to each relevant job opening. The feminine woman was invited by $43.38 \%$ of all contacted firms, the masculine one by $42.65 \%$, which means that the feminine female was more successful by 0.74 percentage points. The null hypothesis that the two women were treated the same could not be rejected. Second, applications of the feminine straight female and the masculine lesbian were sent out to all firms. The

Table 1

(a) Effect of sexual orientation on masculine female

\begin{tabular}{llll}
\hline & $\begin{array}{l}\text { Invitation rates- } \\
\text { 1st round }\end{array}$ & Invitation rates- \\
2nd round
\end{tabular}

\begin{tabular}{|c|c|c|c|c|}
\hline & \multicolumn{3}{|c|}{$\begin{array}{l}\text { Invitation rates- } \\
1 \text { st round }\end{array}$} & \multirow[t]{2}{*}{$\begin{array}{l}\text { Invitation rates- } \\
\text { 3rd round }\end{array}$} \\
\hline$N=272$ & & & $N=170$ & \\
\hline Masculine straight, MS & \multicolumn{2}{|l|}{$42.65 \%$} & Masculine straight, MS & $48.82 \%$ \\
\hline Feminine straight, FS & \multicolumn{2}{|l|}{$43.38 \%$} & Feminine lesbian, FL & $36.47 \%$ \\
\hline Difference, MS - FS & \multicolumn{2}{|c|}{$-0.74 \%$} & Difference, MS - FL & $12.35 \%$ \\
\hline \multicolumn{5}{|c|}{$\begin{array}{l}\text { Effect of sexual orientation, } \\
\quad \text { difference in differences }(\mathrm{FS}-\mathrm{FL})=-13.09 \% *\end{array}$} \\
\hline
\end{tabular}


feminine straight applicant was successful in $60.82 \%$ of all cases, the masculine lesbian in $47.95 \%{ }^{16}$ This represents an advantage of the feminine straight female of 12.87 percentage points. Remember that this difference occurs, although both individuals apply to the same firms, i.e. firm specific effects are controlled for. What is of central interest, though, is the comparison between the masculine straight and lesbian female, which can only be obtained via the difference in differences: The advantage of the feminine straight woman over the masculine woman increases from 0.74 percentage points to 12.87 percentage points, when the latter indicates lesbian orientation. This indicates an advantage of the straight masculine female over her lesbian counterpart of 12.13 percentage points ${ }^{17}$ and means that the probability of the masculine female to be invited to an interview decreases by 12.13 percentage points when she reveals a lesbian orientation. $^{18}$

\subsection{Discrimination against feminine woman}

Table $1 \mathrm{~b}$ demonstrates the effect of sexual orientation on the feminine female. As has been noted before, the straight feminine female has an advantage over her masculine counterpart of 0.74 percentage points. In the next step, the masculine straight female and the feminine lesbian applied for the same jobs. The masculine straight woman was invited to an interview by 48.82 percentage points of all contacted firms, the feminine lesbian by 36.47 percentage points. Consequently, the masculine straight woman had an advantage compared to the feminine lesbian of 12.35 percentage points. Calculating the difference in differences (DD), we see that the declaration of her sexual preference decreases the feminine female's chances to be invited for an interview by 13.09 percentage points. ${ }^{19}$

The underlying assumption of the DD experiment is that while the absolute values of invitation rates for the straight applicants can be different in each stage, e.g. due to the business-cycle or-as is more likely in our experiment-seasonal changes, the differences in invitation rates must be invariant over the different stages of the experiment. $^{20}$

16 The high overall rates of invitations in the second round are rather striking and must be due to seasonal changes. Other exogenous changes of labor demand or other macroeconomic variables are possible but unlikely within this short time period, since there were no observable changes in the business cycle.

17 Investigating discrimination for the two occupational subcategories separately, we find significant discrimination against the masculine lesbian only for secretaries. This might be due to the fact that normative heterosexuality is more of an inherent requirement for secretaries while accountants often work autonomously and have even less contact with clients and customers.

18 The negative effect of discrimination is significant at the $5 \%$ level using a one-sided test.

19 Again, this effect is significantly different from zero at the 5\% level.

20 When indicating a lesbian orientation, the invitation rate of the feminine female decreases by a higher amount $(13.09 \%)$ than that of the masculine one $(12.13 \%)$; nevertheless, the difference between the two gender types is statistically insignificant $(13.09-12.13=0.96$. The difference of 0.0096 lies within the confidence interval for $\alpha=5 \%$, which is $[-0.226,0.245]$ ). This implies both women have an identical disadvantage when disclosing their sexual preference. 
Table 2

Invitation to an interview

\begin{tabular}{lcc}
\hline & Logit (marginal effects) & \\
\cline { 2 - 3 } & $(1)$ & $(2)$ \\
\hline Masculine gender & $-0.004(0.15)$ & $-0.007(0.17)$ \\
Lesbian sexual orientation & $-0.126(3.39)^{* *}$ & $-0.131(2.00)^{*}$ \\
Masculine lesbian & $0.177(4.56)^{* *}$ & $0.011(0.10)$ \\
Round 2 & $0.059(1.49)$ & $0.175(3.62)^{* *}$ \\
Round 3 & 1226 & $0.062(1.27)$ \\
Observations & & 1226 \\
\hline
\end{tabular}

Absolute value of $z$-statistics in parentheses.

* Significant at $5 \%$.

** Significant at $1 \%$.

The effects of sexual orientation and gender are also presented in Table 2, where the probability of being invited to an interview is estimated with a logit model. The observed values are 0 and 1, i.e. not invited, invited to an interview. The probability of being invited to an interview is estimated as a function of gender (femininity versus masculinity) and sexual orientation. The table presents marginal effects. Since the different rounds took place sequentially, they are included in the estimation to control for time-effects. No other controls are necessary since the applicants are matched in all other characteristics than gender and sexual orientation. While gender does not have an effect on invitation rates (neither feminine nor masculine women are preferred by employers), sexual orientation has very much so. As has been seen before, an indicator for lesbian orientation reduces the probability to be invited to an interview by 13.10 percentage points for the feminine and 12 percentage points for the masculine female. This means indicating a lesbian orientation when applying for a job triggers unfavorable treatment while one's personal style (femininity or masculinity) does not seem to matter.

\section{Conclusions}

In this paper we examined the impact of lesbian sexual orientation and gender identity on the chances of getting invited to a job interview. Previous research investigating discrimination based on sexual orientation has provided ambiguous results for lesbians' earnings, usually indicating higher incomes for lesbians. However, this advantage for lesbian workers could be due to a number of different reasons, e.g. selection bias (only high income lesbians disclose their sexual orientation), insufficient controls for occupations, or unobserved differences in productive characteristics. Furthermore, since the available data does not provide information on disclosure on the job, a large number of investigated individuals might not be "out" on the job and therefore not confronted with an income loss - although discrimination based on sexual orientation does occur to those "outed" to the public.

Our experiment allowed to collect data free of any of the previously mentioned flaws, comparing the labor market outcomes for open lesbians and heterosexual women of 
identical productivity in the clerical profession in Austria. Additionally, we tested whether increased masculinity is responsible for lesbians' higher earnings as suggested by Blandford (2003) and Clain and Leppel (2001).

We find that indicating a lesbian identity reduces one's invitation rate by about $12-13$ percentage points, which corresponds with Adam's (1981) results, who finds a 11 percentage points reduction of invitation rates for females in the city of Toronto. Since the experimental setup controlled for productivity, it has to be discrimination which is responsible for this unfavorable treatment of lesbians. Customers' discrimination is an unlikely source for differential treatment since the investigated jobs do not require much customer contact. However, coworkers' discrimination as well as employer's discrimination can be responsible for this outcome. While the bosses of most positions we applied to probably were male, the jobs under investigation were clearly female-dominated and suggest predominantly female coworkers. However, Kite and Whitley (1996) showed in their meta-study that - although men hold more negative attitudes toward gay men - men and women do not significantly differ in their negative attitudes toward lesbians. Consequently, both groups - employers and coworkers - are equally likely to cause differential treatment.

The hypothesis that gender identity might have a separate influence on labor market outcomes could not be verified. This means, at least with respect to being invited to an interview, that increased masculinity neither works as an advantage nor as a disadvantage - neither for straight nor lesbian women.

Although wage regressions indicate higher earnings for lesbian women, the results of this study demonstrate that lesbians are, in fact, not a relatively privileged group, butmuch to the contrary - are subject to discrimination. Their higher incomes may be due to measurement errors or increased productivity. This productivity might be driven by higher effort and on-the-job-training and is possible, since lesbians do carry less household responsibility, but also necessary, because they cannot receive transfers from a partner.

\section{Acknowledgements}

This research was supported by the Allgemeine Sparkasse research prize. Sandra Leitner provided invaluable assistance with the data collection. Thanks to Rudolf Winter-Ebmer, Lee Badgett, Dan Black, Josef Fersterer, seminar participants in Linz and at the ESA meetings in Barcelona as well as an anonymous referee for helpful comments.

\section{References}

Adam, B.D., 1981. Stigma and employability: discrimination by sex and sexual orientation in the ontario legal profession. Canadian Review of Sociology and Anthropology 18 (2), 216-221.

Arrow, K.J., 1973. The theory of discrimination. In: Ashenfelter, O., Rees, A. (Eds.), Discrimination in Labor Markets. Princeton Univ. Press, New Jersey, pp. 3-33.

Averett, S., Korenman, S., 1996. The economic reality of the beauty myth. Journal of Human Resources 31 (2), 304-330. 
Badgett, L.M.V., 1995. The wage effects of sexual orientation discrimination. Industrial and Labor Relations Review 48 (4), 726-739.

Badgett, L.M.V., 1996. Employment and sexual orientation: disclosure and discrimination in the workplace. In: Ellis, A., Riggle, E. (Eds.), Sexual Identity on the Job. Issues and Services. Harrington Park Press, New York, pp. 29-52.

Badgett, L.M.V., 2002. Discrimination based on sexual orientation. A Review of the Literature in Economics and Beyond, manuscript.

Badgett, L.M.V., Donnelly, C., Kibbe, J., 1992. Pervasive Patterns of Discrimination Against Lesbians and Gay Men: Evidence from Surveys Across the United States National Gay and Lesbian Task Force Policy Institute, Washington, DC.

Becker, G.S., 1957. The Economics of Discrimination University of Chicago Press, Chicago.

Bem, S.L., 1974. The measurement of psychological androgyny. Journal of Consulting and Clinical Psychology 42 (2), $155-162$.

Biddle, J.E., Hamermesh, D.S., 1998. Beauty, productivity, and discrimination: lawyers' looks and lucre. Journal of Labor Economics 16 (1), $172-201$.

Black, D.A., Makar, H.R., Sanders, S.G., Taylor, L.J., 2003. The earnings effects of sexual orientation on earnings. Industrial and Labor Relations Review 56 (3), 449-469.

Blandford, J.M., 2003. The nexus of sexual orientation and gender in the determination of earnings. Industrial and Labor Relations Review 56 (4), 622-642.

Clain, S.H., Leppel, K., 2001. An investigation into sexual orientation discrimination as an explanation for wage differences. Applied Economics 33, 37-47.

Firth, M., 1981. Racial discrimination in the British labor market. Industrial and Labor Relations Review 34 (2), $265-272$.

Firth, M., 1982. Sex discrimination in job opportunities for women. Sex Roles 8 (8), 891-901.

Fix, M., Galster, G.C., Struyk, R.J., 1993. An overview of auditing for discrimination. In: Fix, M., Struyk, R.J. (Eds.), Clear and Convincing Evidence. Measurement of Discrimination in America. Urban Institute Press, Washington, DC, pp. 1-67.

Giddings, L.A., in press. The division of labor in same-sex households. In: Moe, K.S. (Ed.), Economics of Gender and the Family. Blackwell, Portland.

Hamermesh, D.S., Biddle, J.E., 1994. Beauty and the labor market. American Economic Review 84 (5), 174-1194.

Heckman, J.J., 1998. Detecting discrimination. Journal of Economic Perspectives 12 (2), $101-116$.

Jones, D.A., 1996. Discrimination against same-sex couples in hotel reservation policies. Journal of Homosexuality $31(1-2), 153-159$.

Kenney, G.M., Wissoker, D.A., 1994. An analysis of the correlates of discrimination facing young Hispanic jobseekers. American Economic Review 84 (3), 674-683.

Kite, M.E., Whitley, B.E., 1996. Sex differences in attitudes toward homosexual persons, behaviors, and civil rights: a meta-analysis. Personality and Social Psychology Bulletin 22 (4), 336-353.

Klawitter, M.M., Flatt, V., 1998. The effects of state and local anti-discrimination policies on earnings for gays and lesbians. Journal of Policy Analysis and Management 17 (4), 658-686.

Laner, M.R., Laner, R.H., 1980. Sexual preference or personal style? Why lesbians are disliked. Journal of Homosexuality 5 (4), 339-356.

McIntyre, S.J., Moberg, D.J., Posner, B.Z., 1980. Discrimination in recruitment: an empirical analysis (comment). Industrial and Labor Relations Review 33 (4), 543-547.

Newman, J.M., 1978. Discrimination in recruitment: an empirical analysis. Industrial and Labor Relations Review 32 (1), 15-23.

Phelps, E.S., 1972. The statistical theory of racism and sexism. American Economic Review 62 (4), $659-661$.

Plug, E., Berkhout, P., in press. Effects of sexual preferences on earnings in the Netherlands. Journal of Population Economics.

Riach, P.A., Rich, J., 1991. Testing for racial discrimination in the labor market. Cambridge Journal of Economics 15, 239-259.

Riach, P.A., Rich, J., 1995. An investigation of gender discrimination in labor hiring. Eastern Economic Journal 21 (3), 343-356. 
Riess, B.F., Safer, J., Yotive, W., 1974. Psychological test data on female homosexuality: a review of the literature. Journal of Homosexuality 1 (1), 71-85.

Walters, A.S., Curran, M.-C., 1996. "Excuse me, sir? May I help you and your boyfriend?: salespersons' differential treatment of homosexual and straight customers. Journal of Homosexuality $31(1-2), 135-152$.

Weichselbaumer, D., in press. Is it sex or personality? The impact of sex-stereotypes on discrimination in applicant selection. Eastern Economic Journal. 